SHORT REPORT

\title{
The use of contact lenses to treat visually symptomatic congenital nystagmus
}

\author{
V Biousse, R J Tusa, B Russell, M S Azran, V Das, M S Schubert, M Ward, N J Newman
}

J Neurol Neurosurg Psychiatry 2004;75:314-316. doi: 10.1136/jnnp.2003.010678

It has been suggested that contact lens wear improves the visual function of patients with visual loss from congenital nystagmus. In this study, four patients with congenital nystagmus had two evaluations separated by at least one week (one with spectacles, one with contact lenses) including visual acuity, contrast sensitivity, oscillopsia scale, quality of life questionnaire (NEI VFQ-25), and eye movement recording with an infrared tracking system. All patients subjectively preferred contact lenses to spectacles. Their contrast sensitivity and VFQ-25 scores were improved with contact lenses compared with spectacles alone. Several parameters of nystagmus showed no change in two patients, worsening in one patient and improvement in one patient. This suggests that much of the clinical improvement observed in our patients may result from a better optical correction of their refractive error with contact lenses than with spectacles, rather than from a true damping effect of the nystagmus by contact lenses.

F or human beings to see an object optimally, the image of the object must be held steady upon the foveal region of the retina. By disrupting steady fixation, nystagmus degrades vision. ${ }^{1-3}$ Furthermore, if the image of the object is moved from the fovea to the peripheral retina, it will be seen less clearly. Indeed, visual symptoms caused by nystagmus usually correlate with the speed of the slow phase of the nystagmus, the extent of displacement of the image of the object from the fovea, and in the case of congenital nystagmus, the duration of the foveation period, during which the image of the target is relatively stationary in the foveal area. ${ }^{1-3}$

The treatment of nystagmus is limited. ${ }^{12}{ }^{2}$ A few studies have suggested that the use of contact lenses improves the visual function of patients with congenital nystagmus, ${ }^{5-8}$ although the effects of contact lenses on nystagmus remain debated $^{125-8}$ and only a few neurologists offer this treatment to their patients. It is possible that contact lenses may correct a patient's refractive error better than spectacles. Indeed, the contact lens moves with the eye, therefore the patient looks along the visual axis of the correcting lens for a far greater proportion of the time than with spectacles. Contact lenses provide more continuous fixation than spectacles, reducing the spherical and chromatic aberration, together with the prismatic effect. $^{569}$ In addition, contact lenses generate additional vergence and accommodative effort, both of which decrease congenital nystagmus in some patients. ${ }^{125-8}$ It has also been suggested that contact lens wear may damp nystagmus by decreasing the nystagmus' amplitude and frequency. ${ }^{25-8}$ This phenomenon might be due to sensory feedback from movement of the edge of the lens against the edges and inside of the lids as the eyes oscillate (mediated through trigeminal afferents). ${ }^{2}{ }^{7}$ This effect does not seem to be related to the mass of the lens. ${ }^{7}$

To determine if contact lens wear improves visual function and decreases nystagmus in patients with congenital nystagmus, we did a prospective, crossover study between spectacles and contact lens wear.

\section{METHODS}

Four patients with congenital nystagmus were prospectively included in our study. The study was approved by our institutional review board. Our inclusion criteria were decreased visual function related to the nystagmus (assessed by best corrected binocular visual acuity worse than or equal to 20/40, but at least 20/400), 18 years of age or older, willingness to participate in the study, and informed consent. Patients were excluded from the study if they were not willing or incapable of using contact lenses (for example, because of poor hygiene, poor compliance, or corneal disease contra-indicating contact lens wear), or if they had an ocular disease sufficient to cause the visual acuity obtained.

All patients underwent complete baseline neuro-ophthalmological, neurological and ocular evaluations, including refraction, slit lamp examination, intra-ocular pressures, dilated funduscopy, confrontation visual fields, extra-ocular movements, characterisation of the nystagmus, and brain magnetic resonance imaging if neuro-imaging was found to be necessary. Contact lens fitting was performed in the contact lens service. All patients were told to wear their contact lenses during the day only. Once the patients were accustomed to their contact lenses, they underwent two evaluations separated by at least one week.

During the first visit, the patients were evaluated with spectacles only, and during the second visit, they were evaluated with contact lenses on (they were asked to wear their contact lenses the week prior to their second evaluation and to come to the eye clinic with contact lenses on). Each evaluation included visual acuity and contrast sensitivity for each eye and with both eyes open. Patients with a null point were asked to avoid their null point position during the evaluation. In addition, a quality of life questionnaire (NEI VFQ-25) was administered to each patient. ${ }^{10}$ At the end of the study, the patients were asked whether they subjectively preferred spectacles or contact lenses.

Eye movement recording was performed at each visit with a computer analysed, infrared eye tracker at a sampling rate of $1000 \mathrm{~Hz} .{ }^{11}$ For the first evaluation, the recording was performed with the patients wearing their spectacles. For the second evaluation, the patients wore their contact lenses. The patient fixated a centre target light and read small letters one metre away for 15 seconds. Five to 10 continuous cycles were analysed at the centre of gaze in the middle of each data

Abbreviation: VFQ-25, quality of life questionnaire 
period of data collection. Frequency, peak amplitude, peak velocity and duration of the foveation period were recorded for each cycle during reading.

\section{RESULTS}

Our four patients had congenital nystagmus, two related to albinism (table 1). All had normal funduscopic examinations. All patients had refractive errors corrected with spectacles. Best corrected visual acuity ranged from 20/40 to 20/400. All were fitted with soft contact lenses. All patients subjectively preferred contact lenses to spectacles. Their visual acuity was slightly improved with contact lenses compared with spectacles alone (mean visual acuity OU improved from 20/ 64 to 20/40). When both eyes were tested separately, contrast sensitivity was improved with contact lenses compared with spectacles alone, but was not improved with both eyes open. Quality of life (VFQ-25) was improved with contact lenses compared with spectacles alone (Mean VFQ-25 score improved from 64.7 to 72.05 ). Eye movement recording to analyse mean peak amplitude, peak velocity, and duration of the foveation period showed no change in two patients (patients 3 and 4), improvement in one patient (patient 1), and worsening in one patient (patient 2) (table 2). Nystagmus frequency did not change in any patient.

\section{DISCUSSION}

This study confirms the positive therapeutic effect of contact lenses in some patients with congenital nystagmus for whom few treatments are available. Much of the clinical improvement observed in our patients may result from a better optical correction of their refractive error with contact lenses than with spectacles, rather than a true damping effect of the nystagmus by contact lens wear. It is also possible that contact lenses had a placebo effect on our patients who strongly believed contact lenses helped them with daily activities. Visual acuity was slightly improved in all patients, and their contrast sensitivity was better with contact lens wear.

All patients had an important refractive error that was most likely better corrected with contact lenses than with spectacles. Indeed refractive disorders are more common in patients with congenital nystagmus than in the general population, and accurate refraction is the best way to improve visual acuity in patients with nystagmus. ${ }^{9}$ However, because of his severe astigmatism, patient 4 used plano contact lenses in addition to spectacles correcting his refractive error, and the slight improvement of his visual function could not be explained by the optical correction itself.

Contact lens wear improved our patients' quality of life. Indeed, the VFQ-25 questionnaire evaluating patients' quality of life based on their visual function was improved in all patients. All our patients preferred contact lenses to spectacles alone. They all felt that their visual function self confidence was improved with contact lenses. All emphasised better performance at work, during interactions with a group (such as during teaching), or while driving with their contact lenses on. Their explanation varied from "I feel I can see better" to "I look better without my glasses" suggesting an important placebo effect of the contact lenses. Indeed, it is well known that visual acuity of patients with congenital nystagmus fluctuates with both the mental state (level of attention, excitement, or anxiety) and the visual task. ${ }^{13}$ Therefore, increasing the confidence of patients with congenital nystagmus may have a significant impact on their quality of life.

In our study, the eye movement recordings showed that contact lenses had no or, at most, a moderate effect on the nystagmus itself. It has been suggested that contact lenses may damp the nystagmus itself, ${ }^{2-8}$ but this was not observed in three of our four patients. We chose to not use the more

Table 1 Clinical characteristics of our four patients

\begin{tabular}{|c|c|c|c|c|c|c|c|c|c|c|c|c|c|c|}
\hline \multirow[b]{2}{*}{ Patient } & \multirow{2}{*}{$\begin{array}{l}\text { Age } \\
\text { Sex }\end{array}$} & \multirow[b]{2}{*}{ Nystagmus } & \multirow{2}{*}{$\begin{array}{l}\text { Ophthalmological } \\
\text { evaluation }\end{array}$} & \multirow{2}{*}{$\begin{array}{l}\text { Refraction/Contact } \\
\text { Lens Type }\end{array}$} & \multicolumn{3}{|c|}{ VA EDTRS } & \multicolumn{3}{|c|}{ VA Snellen } & \multicolumn{3}{|c|}{$\begin{array}{l}\text { Contrast } \\
\text { Sensitivity }\end{array}$} & \multirow[b]{2}{*}{ VFQ-25 } \\
\hline & & & & & OD & os & OU & OD & os & OU & $O D$ & os & OU & \\
\hline 1 & $64 \mathrm{M}$ & $\begin{array}{l}\text { Congenital } \\
\text { Pendular } \\
\text { Latent }\end{array}$ & $\begin{array}{l}\text { Albinism. } \\
\text { Blue iris, } \\
\text { Transillumination } \\
\text { defects. } \\
\text { Blonde fundus. } \\
\text { 10D ET }\end{array}$ & $\begin{array}{l}\text { OD:+3.75+3.00×135 } \\
\text { OS: }+3.50+1.75 \times 32 \\
\text { Bitoric CL } \\
\text { Diameter: } 8.8 \mathrm{~mm}\end{array}$ & & & & & & & & & & \\
\hline \multicolumn{3}{|c|}{$\begin{array}{l}\text { No contact lens } \\
\text { With contact lens }\end{array}$} & & & $\begin{array}{l}29 \\
36\end{array}$ & $\begin{array}{l}35 \\
43\end{array}$ & $\begin{array}{l}33 \\
45\end{array}$ & $\begin{array}{l}20 / 126- \\
20 / 100+\end{array}$ & $\begin{array}{l}20 / 100 \\
20 / 64-\end{array}$ & $\begin{array}{l}20 / 100- \\
20 / 64-\end{array}$ & $\begin{array}{l}29 \\
33\end{array}$ & $\begin{array}{l}34 \\
37\end{array}$ & $\begin{array}{l}32 \\
35\end{array}$ & $\begin{array}{l}58.79 \\
65.25\end{array}$ \\
\hline 2 & $18 \mathrm{M}$ & $\begin{array}{l}\text { Congenital } \\
\text { Pendular } \\
\text { Latent }\end{array}$ & Normal 5D ET & $\begin{array}{l}\text { OD: }-5.00+0.50 \times 90 \\
\text { OS: }-4.50+0.50 \times 90 \\
\text { Soft CL } \\
\text { Diameter: } 8.2 \mathrm{~mm}\end{array}$ & & & & & & & & & & \\
\hline \multicolumn{3}{|c|}{$\begin{array}{l}\text { No contact lens } \\
\text { With contact lens }\end{array}$} & & & $\begin{array}{l}50 \\
55\end{array}$ & $\begin{array}{l}44 \\
53\end{array}$ & $\begin{array}{l}50 \\
59\end{array}$ & $\begin{array}{l}20 / 50 \\
20 / 40\end{array}$ & $\begin{array}{l}20 / 64- \\
20 / 40-\end{array}$ & $\begin{array}{l}20 / 50 \\
20 / 32\end{array}$ & $\begin{array}{l}24 \\
36\end{array}$ & $\begin{array}{l}32 \\
36\end{array}$ & $\begin{array}{l}34 \\
40\end{array}$ & $\begin{array}{l}80.08 \\
88.14\end{array}$ \\
\hline 3 & $24 \mathrm{~W}$ & $\begin{array}{l}\text { Congenital } \\
\text { Pendular } \\
\text { Latent }\end{array}$ & Normal & $\begin{array}{l}\text { OD:- } 1.75+0.75 \times 100 \\
\text { OS: }-2.25+2.00 \times 100 \\
\text { Soft/Toric CL OS } \\
\text { Diameter: } 8.7 \mathrm{~mm}\end{array}$ & & & & & & & & & & \\
\hline \multicolumn{3}{|c|}{$\begin{array}{l}\text { No contact lens } \\
\text { With contact lens }\end{array}$} & & & $\begin{array}{l}22 \\
31\end{array}$ & $\begin{array}{l}45 \\
44\end{array}$ & $\begin{array}{l}69 \\
69\end{array}$ & $\begin{array}{l}20 / 200 \\
20 / 126\end{array}$ & $\begin{array}{l}20 / 64 \\
20 / 64\end{array}$ & $\begin{array}{l}20 / 32- \\
20 / 20-\end{array}$ & $\begin{array}{l}24 \\
33\end{array}$ & $\begin{array}{l}34 \\
36\end{array}$ & $\begin{array}{l}41 \\
41\end{array}$ & $\begin{array}{l}61.14 \\
70.58\end{array}$ \\
\hline 4 & 26M & $\begin{array}{l}\text { Congenital } \\
\text { Pendular } \\
\text { Latent }\end{array}$ & $\begin{array}{l}\text { Albinism. } \\
\text { Blue iris. } \\
\text { Transillumination } \\
\text { defects. } \\
\text { Blonde fundus. } \\
\text { Flick XT }\end{array}$ & $\begin{array}{l}\text { OD: }-3.00+3.75 \times 95 \\
\text { OS:plano+4.25 } \times 95 \\
\text { Plano/soft CL with } \\
\text { spectacles } \\
\text { Diameter: } 14.5 \mathrm{~mm}\end{array}$ & & & & & & & & & & \\
\hline \multicolumn{3}{|c|}{$\begin{array}{l}\text { No contact lens } \\
\text { With contact lens }\end{array}$} & & & $\begin{array}{l}33 \\
36\end{array}$ & $\begin{array}{l}38 \\
45\end{array}$ & $\begin{array}{l}43 \\
46\end{array}$ & $\begin{array}{l}20 / 100- \\
20 / 100\end{array}$ & $\begin{array}{l}20 / 80- \\
20 / 64\end{array}$ & $\begin{array}{l}20 / 64 \\
20 / 50\end{array}$ & $\begin{array}{l}30 \\
33\end{array}$ & 28 & 32 & 58.79 \\
\hline
\end{tabular}

M, man; W, Woman; ET, esotropia; XT, exotropia; VA, visual acuity. EDTRS visual acuity was measured using the New-York Lighthouse charts (Lighthouse Low Vision Products, Long Island City, NY) recorded as the number of letters read with each eye and with both eyes open.

Contrast sensitivity was measured on a contrast sensitivity chart, recorded as the number of letters for each eye and with both eyes open. 


\begin{tabular}{|c|c|c|c|c|c|}
\hline Patient & $\begin{array}{l}\text { Frequency } \\
\text { mean }\end{array}$ & $\begin{array}{l}\text { Peak amplitude } \\
\text { mean (SD) }\end{array}$ & $\begin{array}{l}\text { Peak velocity } \\
\text { mean (SD) }\end{array}$ & $\begin{array}{l}\text { Foveation } \\
\text { time }<4 d / s \&-2 d\end{array}$ & Comments \\
\hline 1 & & & & & Improved \\
\hline No contact lens & 1.00 & $9.89+/-1.23$ & $75.55+/-15.50$ & $12.5 \%$ & \\
\hline With contact lens & 1.00 & $1.13+/-0.37$ & $13.35+/-12.58$ & $25.8 \%$ & \\
\hline 2 & & & & & Worse \\
\hline No contact lens & 2.25 & $3.87+/-1.12$ & $40.08+/-12.09$ & $15.7 \%$ & \\
\hline $\begin{array}{l}\text { With contact lens } \\
3\end{array}$ & 2.50 & $5.47+/-1.30$ & $76.05+/-12.71$ & $7.6 \%$ & No change \\
\hline No contact lens & 2.25 & $0.97+/-0.50$ & $6.54+/-4.49$ & $57.2 \%$ & \\
\hline $\begin{array}{l}\text { With contact lens } \\
4\end{array}$ & 2.00 & $0.80+/-0.35$ & $8.64+/-3.00$ & $52.3 \%$ & No change \\
\hline No contact lens & 7.56 & $1.04+/-0.50$ & $37.53+/-9.67$ & $\begin{array}{l}16.2 \% \\
177 \%\end{array}$ & \\
\hline With contact lens & 8.29 & $0.75+/-0.17$ & $35.88+/-9.81$ & $17.7 \%$ & \\
\hline
\end{tabular}

sensitive search coil method because of the use of topical anaesthesia and scleral coil used with that technique, which would have made it impossible to isolate and evaluate the proposed effect of the contact lenses via a sensory feed back mechanism. ${ }^{1}$ It is possible that a true damping effect would be more obvious in patients with acquired nystagmus and severe oscillopsia than in patients with congenital nystagmus. ${ }^{4}$

There are problems with the use of contact lenses in nystagmus. Fitting is technically difficult and requires multiple measurements of keratometry. Finally, placing a contact lens in a moving eye is difficult, especially when an underlying neurological disease decreases the patient's level of dexterity. It has been emphasised that the constant motion of the eyes may cause lens slippage with possible irritation of the cornea, but this was not observed in our patients. Since the mass of the lens does not seem to play any role in the treatment of nystagmus, soft lenses are usually preferred to the less well tolerated hard lenses.

In summary, although we could not demonstrate definite changes on eye movement recording, contact lens wear had a positive effect on our patients with congenital nystagmus. Contact lens wear is a relatively safe and inexpensive treatment, and should be offered to patients with nystagmus and decreased vision.

\section{Authors' affiliations \\ V Biousse, B Russell, M S Azran, M Ward, N J Newman, Department of Ophthalmology, Emory University School of Medicine, Atlanta, GA V Biousse, R J Tusa, V Das, M S Schubert, N J Newman, Department of Neurology, Emory University School of Medicine, Atlanta, GA N J Newman, Department of Neurological Surgery, Emory University School of Medicine, Atlanta, GA}

This study was supported in part by a departmental grant (Department of Ophthalmology) from Research to Prevent Blindness, Inc, New York, NY, and by core grant P30-EY06360 (Department of Ophthalmology) from the National Institutes of Health, Bethesda, Maryland. Dr Newman is a recipient of a Research to Prevent Blindness Lew R Wasserman Merit Award.

Correspondence to: Dr Valérie Biousse, Neuro-ophthalmology Unit, Emory Eye Center. 1365-B Clifton Road, Atlanta, GA 30322, USA; vbiouss@emory.edu

Received 17 February 2003

In final revised form 21 July 2003

Accepted 21 July 2003

\section{REFERENCES}

1 Leigh RJ, Averbuch-Heller L. Nystagmus and related ocular motility disorders. In: Miller NR, Newman NJ, eds. Walsh \& Hoyt's clinical neuroophthalmology, 5th ed. Baltimore, MD: Lippincott, Williams \& Wilkins, 1998;1:1461-1505.

2 Dell'Osso LF. Development of new treatments for congenital nystagmus. Ann N Y Acad Sci 2002;956:361-79.

3 Sheth NV, Dell'Osso LF, Leigh RJ, et al. The effects of afferent stimulation on congenital nystagmus foveation periods. Vision Res 1995;35:2371-82.

4 Leigh RJ, Averbuch-Heller L, Tomsak RL, et al. Treatment of abnormal eye movements that impair vision: strategies based on current concepts of physiology and pharmacology. Ann Neurol 1994;36:129-41.

5 Abadi RV. Visual performances with contact lenses and congenital idiopathic nystagmus. Br J Physiol Opt 1979;33:32-7.

6 Allen ED, Davies PD. Role of contact lenses in the management of congenital nystagmus. Br J Ophthalmol 1983;67:834-6.

7 Dell'Osso LF, Tracis S, Abel L, et al. Contact lenses and congenital nystagmus. Clinical Vision Science 1988;3:229-32.

8 Golubovic S, Marjanovic S, Cvetkovic D, et al. The application of hard contact lenses in patients with congenital nystagmus. Fortschr Ophthalmol 1989:86:535-9.

9 Hertel RW. Examination and refractive management of patients with nystagmus. Surv Ophthalmol 2000;45:215-22.

10 Mangione CM, Lee PP, Guttierrez PR, et al. Development of the 25 item National Eye Institute visual function questionnaire. Arch Ophthalmol $2001 ; 119: 1050-8$.

11 Averbuch-Heller L, Tusa RJ, Fuhry L, et al. Double blind controlled study of gabapentin and baclofen as treatment for acquired nystagmus. Ann Neurol 1997;41:818-25. 